\title{
Comparative Behavior of Wild and Hatchery Reared White Sea Bream (Diplodus sargus) Released on Artificial Reefs Off the Algarve (Southern Portugal)
}

\author{
Pedro G. Lino, Luís Bentes, David Abecasis, Miguel Neves dos Santos \\ and Karim Erzini
}

\begin{abstract}
Three hatchery produced and reared (HPR) and five wild white sea bream (Diplodus sargus) were double tagged with Vemco V8SC-2L acoustic transmitters and Floy Tag T-bar anchor tags, and released on artificial reefs located near a natural reef off the southern coast of Portugal. Passive telemetry was used to monitor movements of the white sea bream over a nine week period from April to June 2007. Differences in behavior at release, habitat association (artificial vs. natural reef), and in daily movements were registered. Wild fish moved from one habitat to the other with increased preference for the artificial habitat during the day, whereas HPR fish showed no site fidelity or consistent daily movement pattern and left the release site soon after release. Comparison of Minimum Convex Polygon (MCP) showed a higher area usage by wild fish. This experiment shows that these artificial reefs are used on a daily basis by wild white sea bream but apparently are not optimal release locations for hatchery produced white sea bream.
\end{abstract}

Keywords Acoustic telemetry · Diplodus sargus · Artificial reef · Natural reef $\cdot$ Hatchery produced and reared

\section{Introduction}

The white sea bream (Diplodus sargus Linne, 1758), is a common species in the Eastern Atlantic Ocean and Mediterranean Sea (Whitehead et al. 1984). It is a highly valued species in Portugal, where catches have been declining since the late 1980s. Since 2001, IPIMAR has been carrying out restocking trials with fish produced and reared at the IPIMAR Aquaculture facilities (EPPO) in Olhão. Previous studies based on conventional tagging (T-bar anchor tags) and underwater surveys showed that reared specimens do not remain near the artificial reefs for long

P.G. Lino $(\bowtie)$

Instituto Nacional dos Recursos Biológicos (INRB)/IPIMAR, Av. 5 de Outubro S/N, 8700-305 Olhão, Portugal

e-mail: plino@cripsul.ipimar.pt 
periods (Santos et al. 2006). However, these findings are limited by the reduced spatial coverage of underwater surveys and the data from conventional tagging, which provides no information on the behavior of the released fish between release and recapture events. Although underwater observations (Santos et al. 2006) showed that restocked white sea bream tend to school with similar sized wild specimens, it is not known if they have the same patterns of habitat use.

Acoustic telemetry is an ideal tool to address questions of movement and activity patterns of fishes (Zeller, 1999), with the latest transmitters being small enough to be implanted in fish weighing as little as $70 \mathrm{~g}$ (Vemco, 2008) while respecting the 2\% Tag : Body Weight Ratio (TBWR) rule of thumb. Although acoustic telemetry has been widely used in the marine environment to track fish movements and resolve habitat use, it has rarely been applied to compare habitat use of stocked hatcheryreared and wild fish (Taylor et al. 2006).

Age and growth, feeding ecology and reproduction of this commercially valuable species have been extensively studied (Man-Wai and Quignard 1982, Rosecchi 1987, Pajuelo and Lorenzo 2002, Lloret and Planes 2003). Other studies on this species indicate that wild Diplodus sargus are resident species (Santos et al. 2005) on artificial reefs (AR), displaying site fidelity and using AR as a refuge (Pepe et al. 1998) and as feeding locations (Leitão et al. 2007). However, little is known about white sea bream daily movements and how this species uses its habitat.

Behavior of cultured fishes following release has important implications for their survival, growth, and reproduction and therefore for the outcome of restocking programs (Huntingford 2004). The use of acoustic telemetry allows for data collection that can lead to a better understanding of the species ecology, namely the home range, habitat association and daily movements, which can be useful for improving conservation and management (Parsons et al. 2003) of the wild stocks and for optimization of restocking actions.

There are few published examples of the use of acoustic telemetry to investigate the movement patterns of Sparidae (e.g. Jadot et al. 2002, Parsons et al. 2003, Egli and Babcock 2004, Jadot et al. 2006). To the best of our knowledge there is only one study from Portugal (Abecasis and Erzini 2008), where several species of this family are particularly commercially important and where a restocking pilot project of native Sparidae species has been under way since 2001.

The main objective of this study was to compare the movement patterns of hatchery reared Diplodus sargus with those of wild caught specimens when released at $20 \mathrm{~m}$ depth on an artificial reef. In addition to some aspects related with surgery methodology and handling optimization, the main foci were on: (i) behavior of fish during and after release; (ii) habitat association; (iii) daily movements; and (iv) area usage.

\section{Material and Methods}

Fish used in this study were from two sources: hatchery produced and reared juveniles of Diplodus sargus from IPIMAR's Fish Production Unit and wild fish of the 


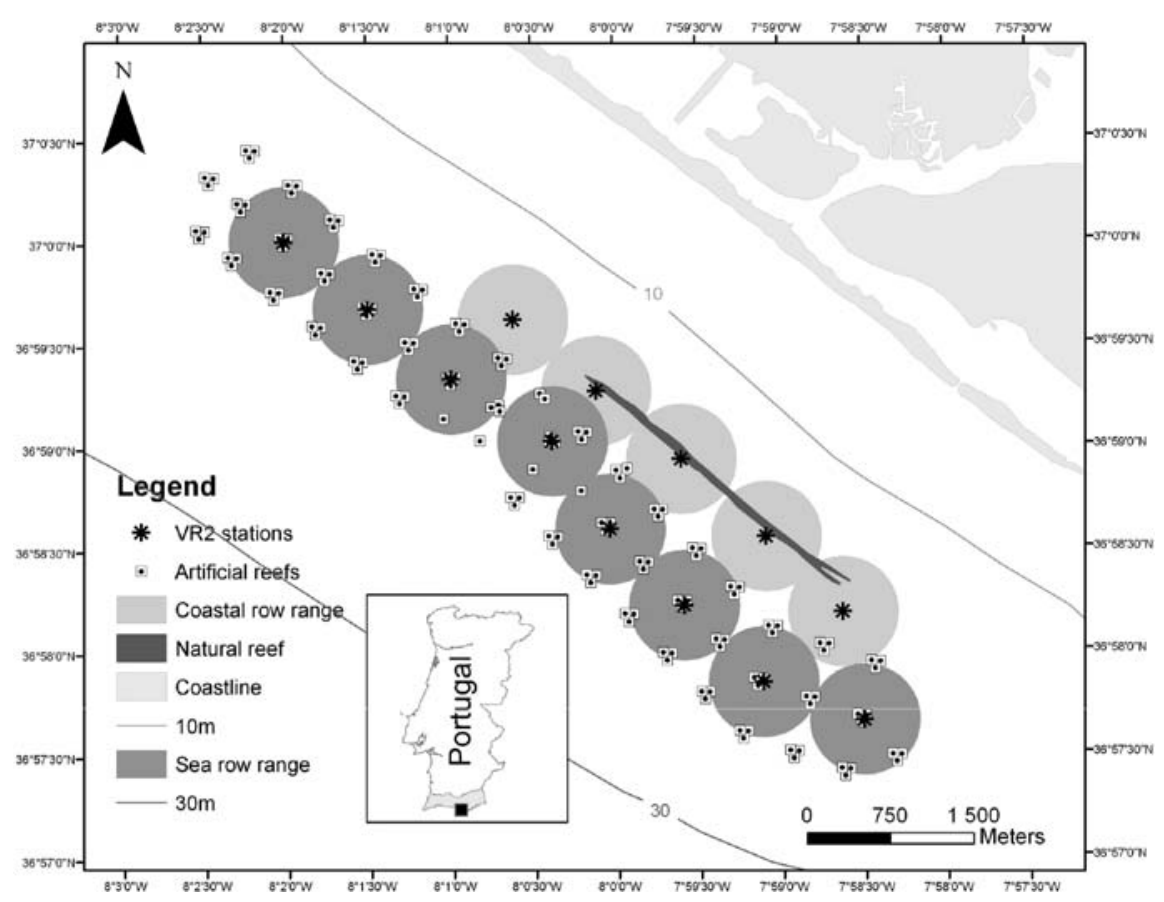

Fig. 1 Location of natural reef, artificial reefs, and VR2 hydrophones off the southern coast of Portugal. The black square in the inlay picture shows the location of the study area

same species captured by longline within the study area. The study area is located in the southern coast of Portugal, at depths between 15 and $30 \mathrm{~m}$ (Fig. 1). This area is composed of two different sets of hard structures: a natural reef, extending for $3 \mathrm{~km}$ and the Faro artificial reef, consisting of several groups of concrete blocks placed at greater depths, seaward from the natural reef, and extending for $8 \mathrm{~km}$.

Wild Diplodus sargus were caught with a baited longline with 400 hooks. The longline was constructed and operated in accordance with local gear specifications (Erzini et al. 1996) by a local fisherman contracted for the study. Hooks were baited with razor shell clam (Ensis siliqua) and the gear set near the seaward edge of the natural reef at day break and hauled regularly every hour until there were few baited hooks left. Fish were slowly hauled to the surface, unhooked and immediately anesthetized. Fish with an inflated bladder were punctured with a hollow needle and carefully massaged until they could swim upright.

HPR fish were the offspring (F1) of a wild caught broodstock. The fish were selected to comply with the $2 \%$ TBWR rule recommended by several authors (Jadot et al. 2005), since no previous studies were made for this species.

All fish were double tagged with a Vemco V8SC-2L acoustic transmitter, surgically implanted in the abdominal cavity, and a Floy Tag T-bar anchor tag below 
the dorsal fin. Both wild and HPR fish were anesthetized in a $0.4 \mathrm{ml} / 1$ 2-phenoxyethanol solution. When the fish were fully anesthetized, showing no reaction to external stimuli (1-2 min), they were measured (Fork Length and Total Length in $\mathrm{cm})$. HPR fish were also weighed to the nearest gram. The TBWR for the HPR fish ranged from 1.4 to $1.7 \%$. The weight for the wild fish was estimated using the weight-length relationship published by Gonçalves et al. (1997) and the TBWR ranged between 0.7 and $1.5 \%$.

Fish were placed in a V-shaped berth, with a $0.2 \mathrm{ml} / \mathrm{l} 2$-phenoxy-ethanol solution being pumped into the fish's mouth. An incision $(\sim 1.5 \mathrm{~cm}$ long) was made at the mid ventral-line, posterior to the pelvic girdle, and the transmitter (disinfected in povidone iodine) was inserted in the peritoneal cavity. On a control HPR batch the wound was closed with one or two individual sutures using nylon monofilament (Braun Dafilon 3/0 DS19 $45 \mathrm{~cm}$ ) and cutting needles. Cyanoacrilate adhesive (Vetseal, B. Braun Medical, Sempach) was used to close the incision and to consolidate the knots. On all other batches the incision was closed with cyanoacrilate adhesive only. The duration of the surgery was under 2 min for each fish.

Hatchery reared fish were placed in a clean holding tank at the IPIMAR aquaculture facilities and monitored for infection and/or tag loss. Wild fish were placed in a holding tank alongside the boat with clean sea water flowing through, until they regained equilibrium (less than $2 \mathrm{~min}$ ).

Fish were released at $20 \mathrm{~m}$ depths on the Faro artificial reef by lowering them in two transport cages (one for wild fish and another for HPR fish), held by scuba divers who constantly monitored their condition during descent. The cages were opened simultaneously at different points on the reef.

The experimental design aimed to maximize the acoustic coverage of the sampling area. An array of 13 VR2 (Vemco) hydrophones was used to track the movements of the tagged fish over an extensive area $\left(10.2 \mathrm{~km}^{2}\right)$ of both natural and artificial reefs. Two rows of receivers were set, with the first located between the natural reef and the artificial reef, and the second among the artificial reef groups. Concrete filled tires and concrete blocks were used to anchor the VR2 receivers and the locations were recorded by GPS. Passive acoustic sampling extended over a period of 9 weeks, from April to June 2007.

The Minimum Convex Polygon (MCP) area was estimated using the MCP function included in ArcGis extension Hawth's Analysis Tools v3.27.

\section{Results}

Fishing with the longline gear took place on the April 19, with five white bream tagged and released on the same day. Three previously tagged HPR were released simultaneously as the wild fish (Table 1). Wild white sea bream were larger than the HPR fish, ranging from 28.9 to $34.2 \mathrm{~cm}$ in total length (TL), while HPR fish were 25.7 to $27.0 \mathrm{~cm}$ TL (Table 1 ). 
Table 1 Characteristics of wild and hatchery produced and reared (HPR) white sea bream, surgery and release dates, and minimum convex polygon. ID is the identification number returned by the pinger, TL is Total Length, TW is Total Weight, and MCP is the Minimum Convex Polygon. NA means the value could not be calculated

\begin{tabular}{llllll}
\hline ID & Source & TL $(\mathrm{cm})$ & TW(g) & Surgery & MCP $\left(\mathrm{km}^{2}\right)$ \\
\hline 113 & Wild & 29.6 & 464 & $19-04-2007$ & 0.697 \\
124 & Wild & 34.2 & 733 & $19-04-2007$ & 2.557 \\
126 & Wild & 28.9 & 430 & $19-04-2007$ & 0.609 \\
127 & Wild & 31.7 & 577 & $19-04-2007$ & 2.104 \\
128 & Wild & 31.1 & 543 & $19-04-2007$ & 2.074 \\
162 & HPR & 25.7 & 313 & $16-04-2007$ & 0.697 \\
163 & HPR & 26.8 & 294 & $16-04-2007$ & 0.571 \\
164 & HPR & 27.0 & 303 & $16-04-2007$ & NA \\
\hline
\end{tabular}

\section{Surgery and Fish Behavior During Transportation and Immediately After Release}

The experiment was quite successful in optimizing handling and surgery time. One batch of 3 HPR fish had their incisions closed with one individual suture and cyanoacrilate, as suggested by the literature (Jadot et al. 2005), while cyanoacrilate alone was used on the second batch. This first group of fish was held under observation for 50 days and was never released. The second group was held for 3 days during which there were no signs of infection and no tag loss. The use of cyanoacrilate alone was also used with the wild fish to simplify procedures on-board the fishing boat.

The fish showed contrasting behavior during transport to the release depth, with hatchery reared fish always swimming towards the surface, while wild fish swam down towards the bottom. When the transport cages were opened, the wild fish immediately swam out, seeking refuge in the artificial reefs while hatchery reared fish refused to leave the cage. When they were forced to exit the cage, some of the HPR fish tried to return inside.

\section{Habitat Association}

The chronogram shows that the wild fish have a clear pattern of use of the natural reef with almost every fish being present in the area during the study period (Fig. 2). For the artificial reef, the habitat use was intermittent, particularly in the last quarter of the study period, showing that for each individual there was an association with the natural reef, with the exception of individuals \#126 and \#128 which visited both habitats daily.

The HPR fish showed no consistent pattern of habitat association. One specimen (\#163) remained in the artificial habitat and then left the study area, while another 


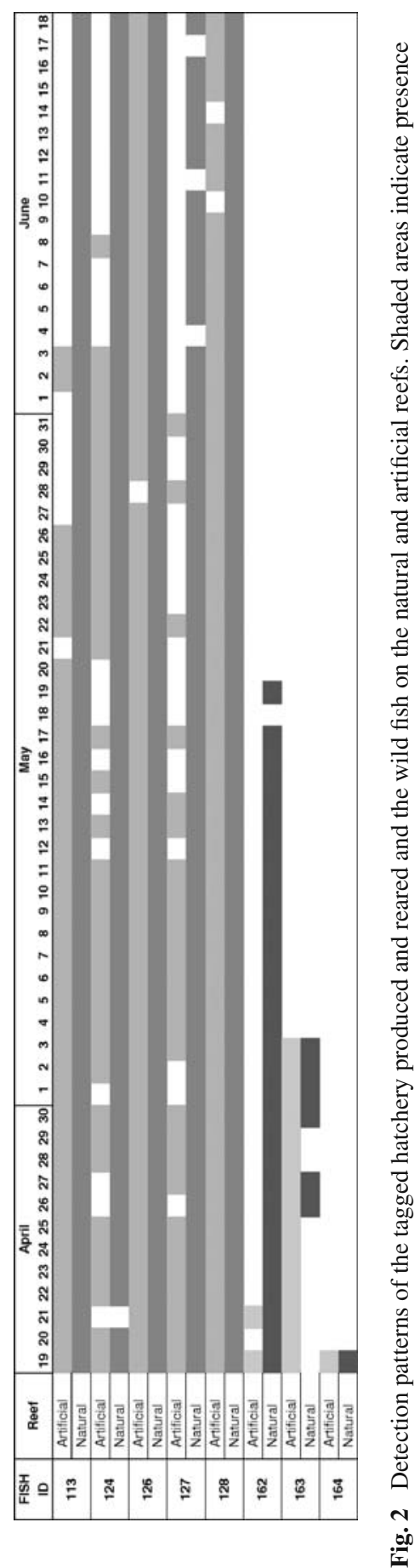


specimen (\#162) did the opposite and a third (\#164) left the study area immediately after release, heading towards the coastline in a northerly direction, instead of taking the closest path in a North-East direction.

\section{Daily Movements and Area Usage}

There was a clear daily movement pattern for the wild fish within the studied area, particularly noticeable on the artificial reefs. The daily movement cycle started about one hour before sunrise and ended by or a few minutes before sunset (Fig. 3a).

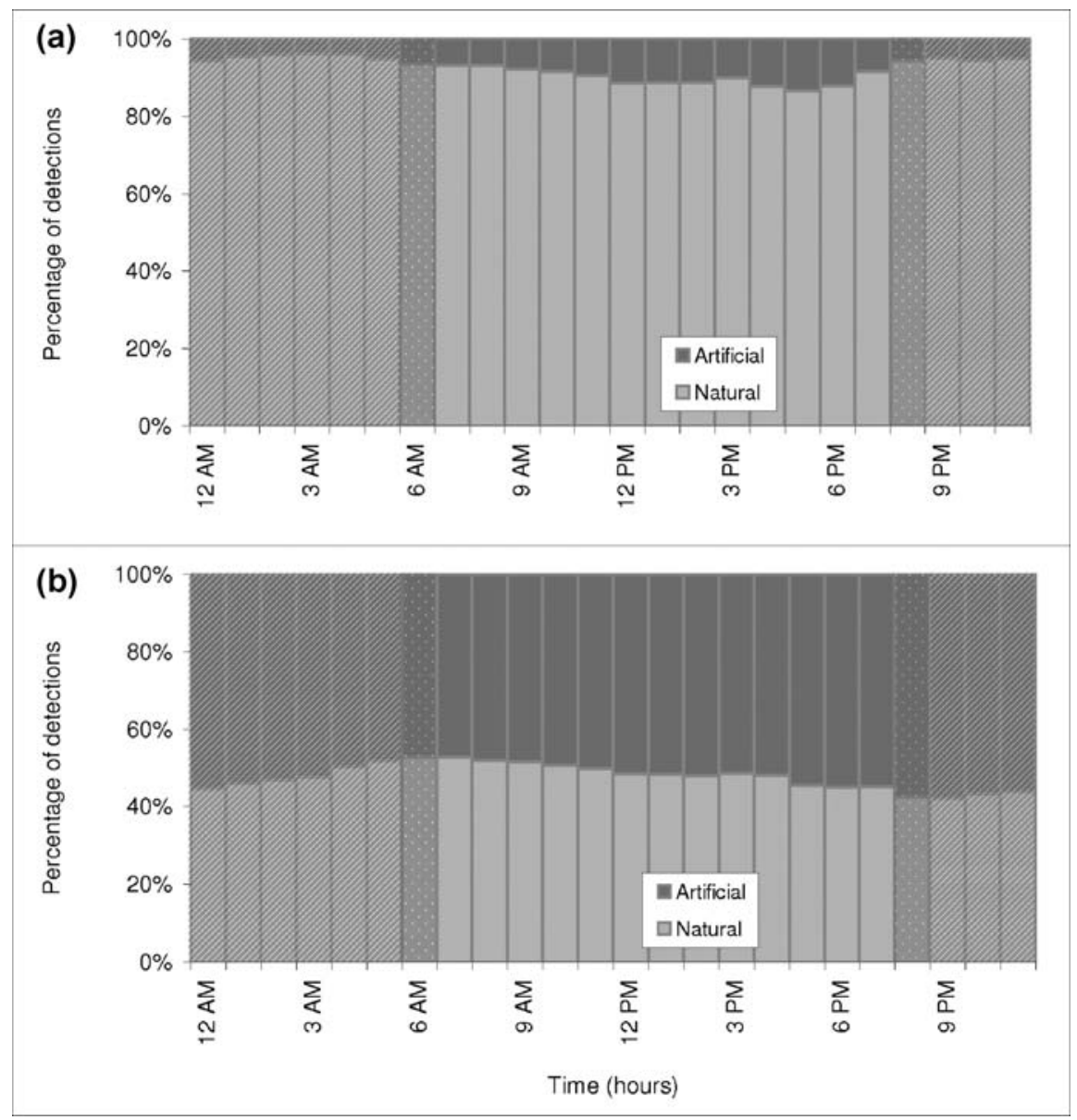

Fig. 3 Daily patterns of habitat use on artificial and natural reefs: (a) wild white sea bream, (b) hatchery produced and reared white sea bream. The dotted area corresponds to sunrise/sunset and the dashed area corresponds to the night period 
Despite a regular circadian rhythm for wild fish, HPR fish did not show any consistent daily patterns (Fig. 3b). The reduction of nocturnal detections for both groups of fish could be explained by a migration to areas out of the range of the acoustic receivers or by the fish sheltering in caves at night, thereby limiting detection.

The MCP area $\left(\right.$ mean \pm SD) was $0.63 \pm 0.09 \mathrm{~km}^{2}$ for the HPR fish and $1.61 \pm 0.89 \mathrm{~km}^{2}$ for the wild fish (Table 1; Fig. 4). The mean MCP areas for the two groups were not significantly different (Mann-Whitney Rank Sum Test, U=8.500, $\mathrm{p}=0.190)$.

\section{Discussion}

In terms of surgery methodology, this experiment was quite successful in optimizing handling and surgery time. The use of cianoacrylate alone reduces handling time and appears to have no negative effects. The long time track of the wild fish movement proves that the surgery was successful and not lethal to the fish (at least for the duration of the study).

Hatchery fish released under the current conditions showed no clear movement pattern. Two different results were observed: (a) leaving almost immediately towards the coastline, (b) remaining in the area 2-4 weeks and leaving thereafter. The observed behavior of the hatchery reared fish is consistent with the underwater observations reported by Santos et al. (2006).

The behavior of the hatchery reared fish is not unexpected since they were reared in shallow tanks, exposed to intense daylight and expected their food to come from the surface. Uglem et al. (2008) also found the same differences between wild caught and hatchery reared cod (Gadus morhua) deliberately released to simulate a cage escape. As in this study, hatchery reared fish dispersed rapidly, in no particular direction. Wild cod remained in the same general area where they were caught, much like the sea bream in our study.

In a previous telemetry experiment carried out by this team (unpublished data) with 4 tagged HPR Diplodus sargus released on another artificial reef, the longest site fidelity in the release area was $31.5 \mathrm{~h}$. The other 3 fish remained $45 \mathrm{~min}, 1 \mathrm{~h}$ and $2.5 \mathrm{~h}$ before moving in different paths towards the coast or shallower waters. However, unlike the present study, the artificial reefs were located on a sandy bottom area with no natural reefs in the vicinity. The results of these two experiments seem to indicate that the presence of a natural, more complex habitat in the vicinity of the release location might increase site fidelity in the short term, even if it is a suboptimal habitat.

Hatchery-reared fish show deficits in virtually all aspects of behavior due to the impoverished conditions in which they are raised (Brown and Laland 2001). According to the same authors, hatchery fish that are many generations removed from their wild counterparts are likely to have more impoverished life-history skills and may take longer to train than those separated by fewer generations. However, this was not the case with the HPR fish used in this study since they were all F1 (first 

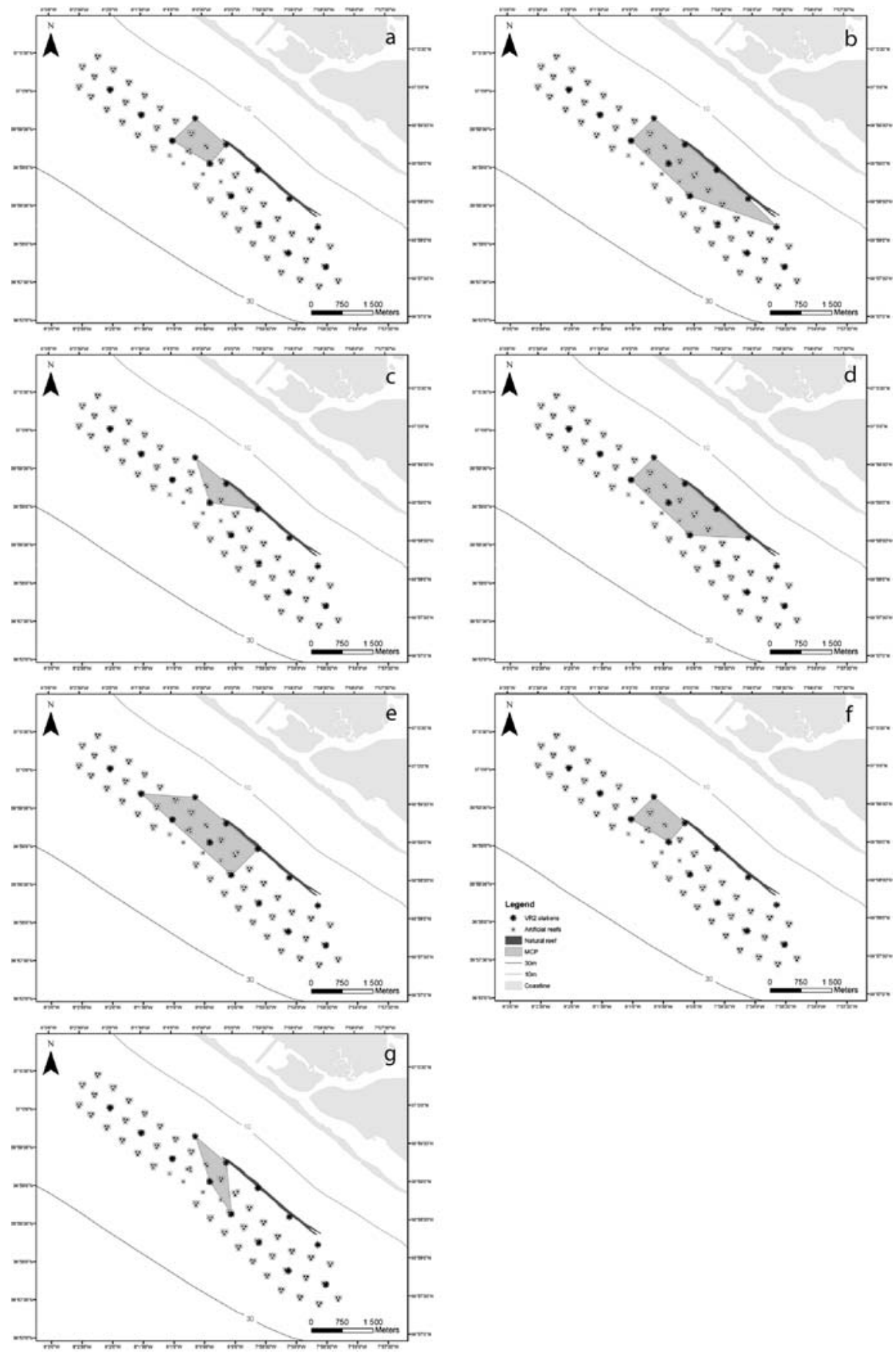

Fig. 4 Minimum Complex Polygon (MCP) of the wild (a-e) and the hatchery produced and reared (f-g) white sea bream 
generation) from a wild broodstock. On the other hand, the differences in behavior seem to increase with the proportion of life spent in captivity (Svasand et al. 2000). This is an expected effect but since it is not possible to tag smaller fish due to battery size/duration limitations, there is currently no technical solution for this dilemma.

From an energetic point of view, it would be interesting to determine if wild white sea bream reduce their movements during the night or if they perform daily migrations to other grounds. Diel behaviors and movements of fish have been reported in many fish species (Yokota et al. 2007), and particularly for some Diplodus species (Santos et al. 2002). However, these daily variations in movements were less obvious for HPR fish. This would not be surprising if the lack of detections at night is due to reduced activity and use of caves, since HPR fish would not be adapted as they are forced to swim continuously in the aquaculture tanks and have no crevices or caves to rest in. Further experiments with this species are scheduled to test the migration versus inactivity hypothesis.

The wild fish used the whole study area with preference for the natural reef. It is interesting from a management point of view to note that they perform daily migrations to the artificial reef. HPR fish did not show a preferential association with any of the habitats.

The MCP values were not statistically different between the two groups of fish. However, they show a wider use of the study area by the wild fish (Fig. 4). This is to be expected since they were released in familiar territory, compared to the HPR fish, which were released in a totally unfamiliar environment. The MCP values for the wild fish were greater than those reported for other similar sized sparidae such as Sparus aurata (Abecasis and Erzini, 2008). However, the latter study was for a lagoon habitat, characterized by extensive channels. Since the tagged fish eventually left the lagoon and were not detected further, the mean MCP of $0.17 \mathrm{~km}^{2}$ should only be considered valid for the juvenile part of the life cycle.

The short residence time and reduced area usage of HPR fish released on these artificial reefs seem to indicate that this is a suboptimal habitat and that releasing fish for restocking purposes on this location may not be appropriate. It is therefore important to assess whether and to what extent present knowledge of the developmental origin of behavioral deficits in cultured fishes can be combined with programs of habitat improvement to make restocking programs more effective (Huntingford, 2004). Further studies on the adaptation of HPR Diplodus sargus are needed to improve their survival in the wild. These include improved migratory, anti-predator and feeding behavior in hatchery fish, as suggested by Brown and Laland (2001) and based on our findings, also by improved daily activity adaptation. Acclimation to the release location using holding cages or pre-adaptation to an artificial habitat that is moved to the release site as well as increasing artificial reef complexity are strategies to be considered in further experiments.

Acknowledgements This study was supported by the EU INTERREg III-A Program (projects GESTPESCA II and PROMOPESCA) and the MARE Program (project "Implantação e estudo integrado de sistemas recifais". We would like to thank to P. Cowley, and three anonymous referees for their comments that helped improve the manuscript. The authors express their gratitude to the staff of IPIMAR's aquaculture station for their careful handling of the hatchery-reared specimens 
and the crew of NI Diplodus for assistance in setting the VR2. We would like to thank Isidoro Costa, skipper of the "Celinha" for carrying out the longline operations and the deployment of some of the VR2 hydrophones. We are grateful to G. D'Anna and V.M. Giacalone from C.N.R.-I.A.M.C. in Castellamare del Golfo, Italy for introducing us to the methods in acoustic telemetry in Sparidae. P. G. Lino holds a PhD grant (SFRH/BD/19308/2004) from Fundação para a Ciência e Tecnologia (FCT).

\section{References}

Abecasis D. and Erzini K. (2008) Site fidelity and movements of gilthead sea bream (Sparus aurata) in a coastal lagoon (Ria Formosa, Portugal). Est. Coast. Shelf Sci. 79, 758-763.

Brown C. and Laland K. (2001) Social learning and life skills training for hatchery reared fish. J. Fish. Biol. 59, 471-493.

Egli D.P. and Babcock R.C. (2004) Ultrasonic tracking reveals multiple behavioural modes of snapper (Pagrus auratus) in a temperate no-take marine reserve. ICES J. Mar. Sci. 61, $1137-1143$.

Erzini K., Gonçalves J.M.S., Bentes L., Lino P. G. and Cruz J. (1996) Species and size selectivity in a multispecies Portuguese artisanal longline fishery. ICES J. Mar. Sci. 53, 811-819.

Gonçalves J.M.S., Bentes L., Lino P.G., Ribeiro J., Canário A.V.M. and Erzini K. (1997) Weightlength relationships for the most important species of the small-scale demersal fisheries of south and south-west coast of Portugal. Fish. Res. 30, 253-256.

Huntingford F.A. (2004) Implications of domestication and rearing conditions for the behaviour of cultivated fishes. J. Fish Biol. 65(Supp.A), 122-142.

Jadot C., Donnay A., Ylieff M. and Poncin P. (2005) Impact implantation of a transmitter on Sarpa salpa behaviour: study with a computerized video tracking system. J. Fish Biol. 67, 589-595.

Jadot C., Ovidio M. and Voss J. (2002) Diel activity of Sarpa salpa (Sparidae) by ultrasonic telemetry in a Posidonia oceanica meadow of Corsica (Mediterranean Sea). Aquat. Liv. Resour. 15, 343-350.

Jadot C., Donnay A., Acolas M.L., Cornet Y. and Bégout Anras M. L. (2006) Activity patterns, home-range size, and habitat utilization of Sarpa salpa (Teleostei: Sparidae) in the Mediterranean Sea. ICES J. Mar. Sci. 63, 128-139.

Leitão F., Santos M.N. and Monteiro C.C. (2007) Contribution of artificial reefs to the diet of the white sea bream (Diplodus sargus). ICES J. Mar. Sci. 64, 473-478.

Lloret J. and Planes S. (2003) Condition, feeding and reproductive potential of white seabream Diplodus sargus as indicators of habitat quality and the effect of reserve protection in the northwestern Mediterranean. Mar. Ecol. Prog. Ser. 248, 197-208.

Man-Wai R. and Quignard J.-P. (1982) The seabream Diplodus sargus (Linne, 1758) in Gulf of Lions: growth of the seabream and characteristics of landings from the commercial fishing grounds of Sète and Grau-du-Roi. Rev. Trav. Inst. Pêches Marit. 46, 173-194.

Pajuelo J.G. and Lorenzo J.M. (2002) Growth and age estimation of Diplodus sargus cadenati (Sparidae) off the Canary Islands. Fish. Res. 59, 93-100.

Parsons D.M., Babcock R.C., Hankin R.K.S., Willis T. J., Aitken J. P., O’Dor R. K. and Jackson G. D. (2003) Snapper Pagrus auratus (Sparidae) home range dynamics: acoustic tagging studies in a marine reserve. Mar. Ecol. Prog. Ser. 262, 253-265.

Pepe P., Badalamenti F. and D’Anna G. (1998) Feeding habits of Diplodus sargus in the artificial reef area of Alcamo Marina (Gulf of Castellamare, North-Western Sicily). Biol. Mar. Medit. 5, $367-370$.

Rosecchi E. (1987) The feeding of Diplodus annularis, Diplodus sargus, Diplodus vulgaris and Sparus aurata (Pisces, Sparidae) in the Lion Gulf and the coastal lagoons. Rev. Trav. Inst. Pêches Marit. 49, 125-141. 
Santos M.N., Monteiro C.C. and Gaspar M.B. (2002) Diurnal variations in the fish assemblage at an artificial reef. ICES J. Mar. Sci. 59, S32-S35.

Santos M.N., Monteiro C.C., Lasserre G. (2005) Observations and trends on the intra-annual variation of the fish assemblages on two artificial reefs in Algarve coastal waters (southern Portugal). Scientia Marina, 69, 415-426.

Santos M.N., Lino P.G., Pousão-Ferreira P. and Monteiro C.C. (2006) Preliminary results of hatched-reared seabream release at artificial reefs off the Algarve coast (southern Portugal): a pilot experiment. Bull. Mar. Sci. 78, 213-219.

Svasand T., Kristiansen T. S., Pedersen T., Salvanes A.G.V., Engelsen R., Naevdal G., and Nodtvedt M. (2000) The enhancement of cod stocks. Fish Fish. 1, 173-205.

Taylor M.D., Laffan S.D., Fielder D.S. and Suthers I.M. (2006) Key habitat and home range of mulloway Argyrosomus japonicus in a south-east Australian estuary: finding the estuarine niche to optimise stocking. Mar. Ecol. Prog. Ser. 328, 237-247.

Uglem I., Bjorn P.A., Dale T., Kerwath S., Okland F., Nilsen R., Aas K., Fleming I. and McKinley R.S. (2008) Movements and spatiotemporal distribution of escaped farmed and local wild Atlantic cod (Gadus morhua L.). Aqua. Res. 39, 158-170.

Vemco (2008) http://www.vemco.com. Accessed February 15, 2008.

Whitehead P.J.P., Bauchot M.L., Hureau J.-C., Nielsen J. and Tortonese E. (eds) (1984) Fishes of the North-Eastern Atlantic and the Mediterranean. Vol. II. UNESCO, Paris.

Yokota T., Masuda R., Arai N., Mitamura H., Mitsunaga Y., Takeuchi H. and Tsuzaki T. (2007) Hatchery-reared fish have less consistent behavioral pattern compared to wild individuals, exemplified by red tilefish studied using video observation and acoustic telemetry tracking. Hydrobiol. 582, 109-120.

Zeller D.C. (1999) Ultrasonic telemetry: its application to coral reef fisheries research. Fish. Bull. 97, 1058-1065. 